\title{
1. Actions and reactions
}

Although the Belt and Road is an initiative of the Chinese Government, it advocates a development model based on China and the whole Asia-Pacific region, as well as covering the globe (Wang Yiwei, 2016: 57).

This book assesses reactions to the implementation of the People's Republic of China's signature policy, entitled Vision and Actions on Jointly Building the Silk Road Economic Belt and 21st Century Maritime Silk Road. Before its publication in 2015 by the National Development and Reform Commission (NDRC, 2015), President Xi Jinping had made two separate announcements. The first in Kazakhstan in September 2013 identified an 'economic belt' for connecting Eurasia; the second in Indonesia in October 2013 recognized a 'maritime road' to link ports in East Asia with counterparts across the Indian Ocean and beyond. Then the two items were joined together into a One Belt One Road policy, which was later rebadged in English as the Belt and Road Initiative. After a slow uptake in 2013, the Initiative has since generated a profusion of commentaries about the policy's scale, scope and implications. Requests to Beijing for clarification of its timeline, and global dimensions and characteristics led to the Vision and Actions statement. The statement outlined not only the government's internal conceptual planning, but also that the policy's implementation promised to change the global economic, political and cultural environment by the mid-twenty-first century.

The underlying logic of the Vision and Actions document is geoeconomics and is best described by the term 'geologistics'. This term was originally coined by the United States military as an alternative to 'geopolitics' for the identification, storage and movement of resources, because of the latter's misuse by Karl Haushofer to underpin the rise of Germany's Third Reich (Sachaklian, 1947). As this alternative did not succeed in replacing geopolitics, the term 'geologistics' is rescued here and used in a broader sense to cover the provision of energy, telecommunications and transport incorporated in economic corridors beyond China's borders; these supply the physical connectivity (infrastructure) and associated institutional connectivity or 'software' for global interactions of even greater intensity (ADB, 2006). These corridors 'link economic agents across specific geographies by connecting hubs that are large concentrations of resources and agents' (Palit, 2018: 204). Their contribution to enhanced global connectivity makes it possible to examine cross-border spillover effects and variable geopolitical and geocultural reac- 


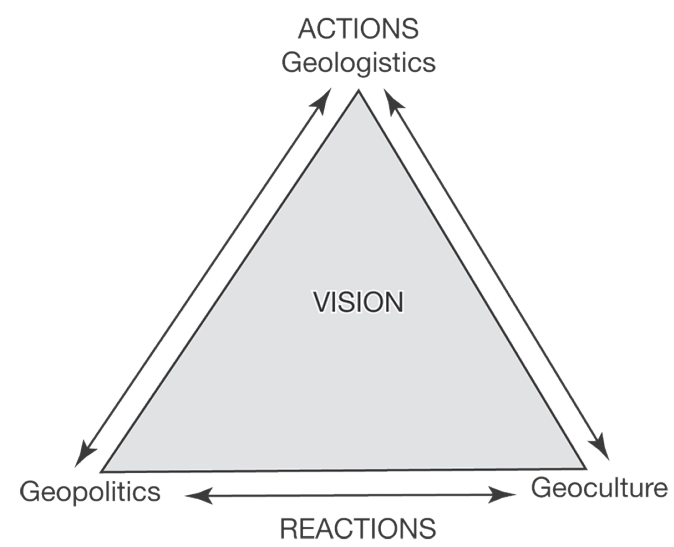

Figure 1.1 Relationships between geologistical actions and geopolitical and geocultural reactions

tions to China's implementation of these geologistics networks (Figure 1.1). Arguably, this triangular framework has its roots in the imperial world of the late nineteenth century when the Great Power 'Great Game' was between imperial Britain and Russia.

Geologistics encompasses China's Belt and Road Initiative's emphasis on corridors, connectivity between places, and cross-border ties to create new markets. Associated with the rapid pace of global and regional integration, this notion contends that economic competition has eclipsed military confrontation at the centre of relations between states. Battles between their competing supply chains are now paramount. Asia's fast-growing economies are perceived as having too much to lose from military confrontation by engaging in activities that destroys trust in their relationships with other countries. This is particularly true for the Great Game's new powers identified by David Scott (2008) as China and India. Such an observation is expected to lead to a reframing of territorial security arrangements to accommodate transnational flows. Further, growth dynamism, energy and regional integration through free trade agreements are seen as the key geologistics drivers necessary to overcome low levels of connectivity in developing countries. These levels concern multinational corporations involved in orchestrating global supply chains in both manufacturing and services, because their managers have difficulties in positioning key nodes within their regional or global production networks. Nevertheless, the proposition that geologistics matters inherent in China's transnational initiative are eroding geopolitical calculations, manifest in trade blocs, barriers and national borders, may be premature. 
Geopolitics is still relevant, given that the Belt and Road Initiative is likely to trigger concerns involving geography, state territoriality, and world power politics inherited from the imperial era. This renewed focus on realist-driven geopolitical calculations in security issues has revived interest in Alfred Thayer Mahan's (1890) ideas on sea power in history. These notions, embodied in the importance of choke points in facilitating the control of sea lanes, have had a deep and abiding effect upon the world view of China's strategists and their audiences on the interplay between geologistics and geopolitics. Such has been the emphasis on the safety and security of sea lanes, as a prerequisite for China to become a maritime power, that some foreign scholars often refer to it as 'Mahan worship' (Tian and Fan, 2019). Also, Eurasia is pertinent to China's geopolitical considerations, because the so-called 'supercontinent' is likely to experience the emergence of fresh security threats and strategic fault lines, new powers and a changing international political order (Figure 1.2). This situation has renewed interest in Sir Halford Mackinder's (1904) dictum that 'who rules the World Island [Eurasia] commands the World' and Nicholas Spykman's (1944) counterpoint that 'who rules the rimland controls Eurasia'. Echoing Mackinder, Zbigniew Brzezinski (1997) has reiterated Eurasia's central primacy; Alexsandr Dugin (1997) has prompted Russia to seek domination of Eurasia (Dunlop, 2004); and, harking back to Alfred Mahan, Peter Navarro (2015), a White House advisor, has provoked the United States to engage in a trade war with China. While Alfred McCoy (2018) suggests that these past and contemporary analysts have brought us to the 'brink of geopolitical disaster', Leszek Buszynski (2019: 1-24) argues geopolitics still has value, not as 'theory', but as an 'approach' for comprehending state behaviour and rivalry within a specific geographical setting.

Geoculture, according to Immanuel Wallerstein (1991: 137), is 'the underside of geopolitics'. As elaborated by Tim Winter (2019), the concept involves the strategic use of historical narrative and heritage for both political and economic ends. This is instanced by the Chinese Government's appeal to the 'spirit' of the ancient Silk Road embodied in the flows of goods, people and ideas (Zhang Y., 2017). The invocation has been used to revive the past peaceful and cooperative activities associated with connectivity and mobility across Eurasia's steppes, deserts and oceans by resuscitating the land-based and maritime routes comprising the 'Silk Road' albeit with Chinese characteristics (Cunliffe, 2015). In the process of establishing the Belt and Road Initiative, the traditional Chinese 'civilization state', as observed by Yiwei Wang (2016: 11), is being transformed for the first time in 5000 years 'from a hinterland civilization to a marine civilization, from an agricultural to an industrial-information civilization, and from a regional to a global civilization'. Further, as characterized by Tim Winter (2020), capitalizing upon the 'civilizational state's' 


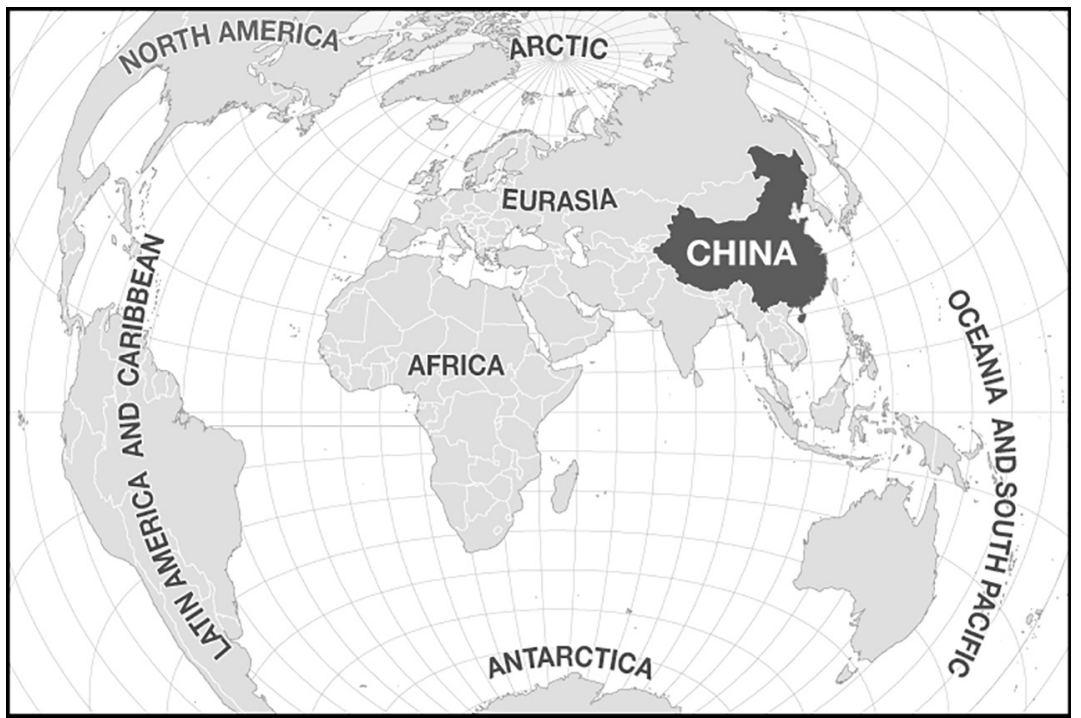

Figure 1.2 China, Eurasia and the rest of the world

geocultural potential will enable the use of China's enhanced connectivity to seek regional or global primacy.

Not only does the Vision and Actions statement prioritise geologistics actions as the driving force behind the Belt and Road Initiative, but it also acknowledges their potential geopolitical and geocultural reactions. Although cast within the Silk Road framework to facilitate trade, build diplomatic relations and generate cross-cultural dialogues, the document's origins are to be found in China's contemporary domestic issues. These are marked by the unequal distribution of economic activities between provinces and cities, and loss of employment in the heavy industry sector. After three decades of accelerated growth since the late 1970s, issues of capital glut, decreasing returns to capital and overproduction in aluminium, cement and steel have been evident since 2006. This situation has been aggravated by China's voracious appetite for reliable imported energy supplies, notably gas and oil, which have to navigate maritime choke points from their origins in the Middle East and Sudan along sea lanes that are patrolled by the United States Navy. These issues are compounded by China's overreliance on supplies of technology from overseas sources and dependence on the United States dollar.

Since 2012 Beijing's response to these issues under President Xi Jinping's leadership has been to seek the Chinese Dream by restoring the country to its rightful position at the centre of the universe. Xi's goal of 'striving to achieve 
national rejuvenation' is being pursued by maintaining the Communist Party of China in power and enhancing its legitimacy (CD, 2017a). As outlined by Kevin Rudd (2019), the latter task involves holding the country together, growing its economy in a sustainable way, securing its maritime borders, reorganizing Eurasia and imbuing international organizations with Chinese standards and values. This process of renewal or rejuvenation has been pursued by taking advantage of the country's capital resources and engineering skills. Since the early 1990s these attributes have been acquired in reshaping the domestic logistics landscape by building infrastructure for air, land and sea transport, energy and telecommunications. The skills are reflected in China's array of new airports, bridges, dams, expressways, fibre-optic cable networks, metropolitan railways, pipelines, ports, special economic zones and tunnels.

It has been but a short step from this domestic logistics activity to bundle the abilities and experience of China's workers together, particularly those in state-owned enterprises, and transfer them into constructing economic corridors in developing countries. This global connectivity push of linking China's internal logistics networks to external ones has created new trade routes by air, land and sea for the country's internationalizing companies to expand markets for their industrial exports. Also, this improved connectivity promises to smooth the inflow of raw materials and food, and provide alternative imported gas and oil supplies. Thus, geologistics has allowed China to adopt David Harvey's (2001) 'spatial fix' to resolve the country's internal structural issues, which has permitted Beijing to play a more assertive role at the centre of shaping and controlling the world economic system.

Since 2017 the Belt and Road Initiative geologistics strategy has been heavily promoted by Chinese media following the establishment of a dedicated website to broaden its appeal. Rather than following a sequential approach, the Initiative comprises a portfolio of overseas infrastructure projects. These projects are designed to boost connectivity, trade and investment by increasing opportunities for the country's businesses 'going global'. Although the Initiative is a multilateral concept, the deals made by China and its companies overseas are bilateral in character and organized through agreements with national governments or, on occasions, with their provincial and even local counterparts. There is no published master plan and there are no official data on investments that stem from concessionary bargaining (Kohli and Linn, 2019a). Also, these investments have not precluded Chinese companies from investing in physical assets within advanced capitalist economies, notably the United Kingdom, Japan, the Netherlands and, to a lesser and dwindling extent, the United States.

Originally, the Belt and Road Initiative was tightly focused upon 64 countries, excluding China, in Asia, Europe and East Africa. Since then the Initiative's scope has been widened beyond its original Eurasian confines to 
further boost policy coordination and investment by Chinese companies across a wider range of continents and countries. By January 2020 the Initiative's continual refocusing and geographical malleability has resulted in it covering 143 countries and spanning other parts of Africa and Eurasia, Oceania and the South Pacific, and Latin America and the Caribbean.

In gauging the differing reactions to China's geologistics model, a distinction is made in discussing the Belt and Road Initiative between the operation of the Silk Road Economic Belt and the Twenty-first Century Maritime Silk Road. Reflecting differences in China's logistics policies towards the country's interior and coastal provinces, this separation between the development of land and sea routes raises a series of issues: How has the Silk Road Economic Belt been developed? How has the Twenty-first Century Maritime Silk Road been orchestrated? And how have participants and non-participants reacted?

The Economic Belt programmes are discussed independently because there is a separate Vision for Maritime Cooperation under the Belt and Road Initiative (Xinhua News Agency, 2017a). This separation is reflected in Beijing's division of the country's international commercial compliance system for resolving disputes between the inland city of Xi' an for the Belt and in the coastal city of Shenzhen for the Road (Mardell, 2018). The distinction between Belt and Road is supported by the rapidly expanding academic literature in logistics that has concentrated upon gauging reactions to either the land-based or the maritime elements (Li et al., 2018). Also, different sets of research tools are required to examine the transcontinental and oceanic spheres of operations that signify that China is shifting from being a traditional land power into a sea power.

The Silk Road Economic Belt is discussed using a framework of landbridges, economic corridors and dry ports that is designed to hasten economic integration to make China the foremost business and technological hub across Eurasia. Two landbridges across Eurasia, and the potential of a third, are identified and examined with reference to specific projects, before discussing the varying reactions from the United States, the European Union, Central and Eastern Europe, Russia, Central Asia and India. Another set of projects are used to examine the three secondary economic corridors connecting China with Pakistan, Indochina and India respectively. New Delhi's reactions to these initiatives are detailed by reference to other corridor projects in South Asia and Southeast Asia in which India is a leading participant.

The Twenty-first Century Maritime Silk Road is considered by invoking an array of blue economic passages, an economic circle and seaport hubs. Originally, these tools were developed to examine the blue economic passage traversing the Indian Ocean and passing through the Suez Canal to the Mediterranean, which prompted India to develop alternative plans for the Bay of Bengal Economic Circle. Since then China's port diplomacy has 
been extended to three other blue economic passages: Oceania and the South Pacific, the Arctic and the Trans-Pacific. China's use of these passages and their seaport hubs has provoked varying reactions from the United States and its allies.

Before discussing where China's Vision and Actions may go next, a second series of issues need to be addressed to assess the reactions to the initial five years of the Belt and Road Initiative between 2013 and 2018 that has packaged trade, industrial expansion and finance. Will China's Initiative unravel with persistent criticism about the nature of its implementation before the project meets Xi Jinping's two centennial goals: (1) the end of the first stage in 2021 marking the 100th anniversary of the Communist Party of China's foundation in Shanghai's French Concession; and (2) the Initiative's completion in 2049 commemorating the 100th anniversary of the People's Republic of China's founding? And relatedly, is there a more preferable model for China's infrastructure development with more stakeholders? Also, is the criticism of China's limited financing provided so far justified? More generally, how has the Belt and Road model affected China? And how different is China's twenty-first-century geologistics model with its emphasis on transport, telecommunications and energy infrastructure from the nineteenth-century British imperial model?

\section{STRUCTURE OF THE BOOK}

The book is structured in three main parts to capture the way China's global development policy, encapsulated in the Belt and Road Initiative, permeates every aspect of the country's foreign policy (Figure 1.3). Part II examines China's logistics system and its transformation into an external geologistics model as an alternative to a Western-led economic system. Part III considers the Silk Road Economic Belt and its key landbridges, economic corridors and dry ports. Part IV studies the Maritime Silk Road and its blue economic passages, an economic circle and seaport hubs.

In Part II, Chapter 2 explores the logistics situation within China, which prompted the initial 2013 'One Belt One Road' strategy, following several unsuccessful attempts by other countries and organizations to revive the Silk Road. By 2015 this geologistics strategy was streamlined soon after the Vision and Actions statement as the 'Belt and Road Initiative', which covered 64 countries. This extensive coverage reflects China's painstaking establishment of treaties with regional groupings and the creation of an underpinning financial superstructure. Also, it has led to the initial identification of key economic corridors and blue economic passages, and the possible extension of the original components to recognize an 'Air Silk Road', a 'Digital Silk Road', an 'Educational Silk Road' and even a 'Space Information Corridor'. 


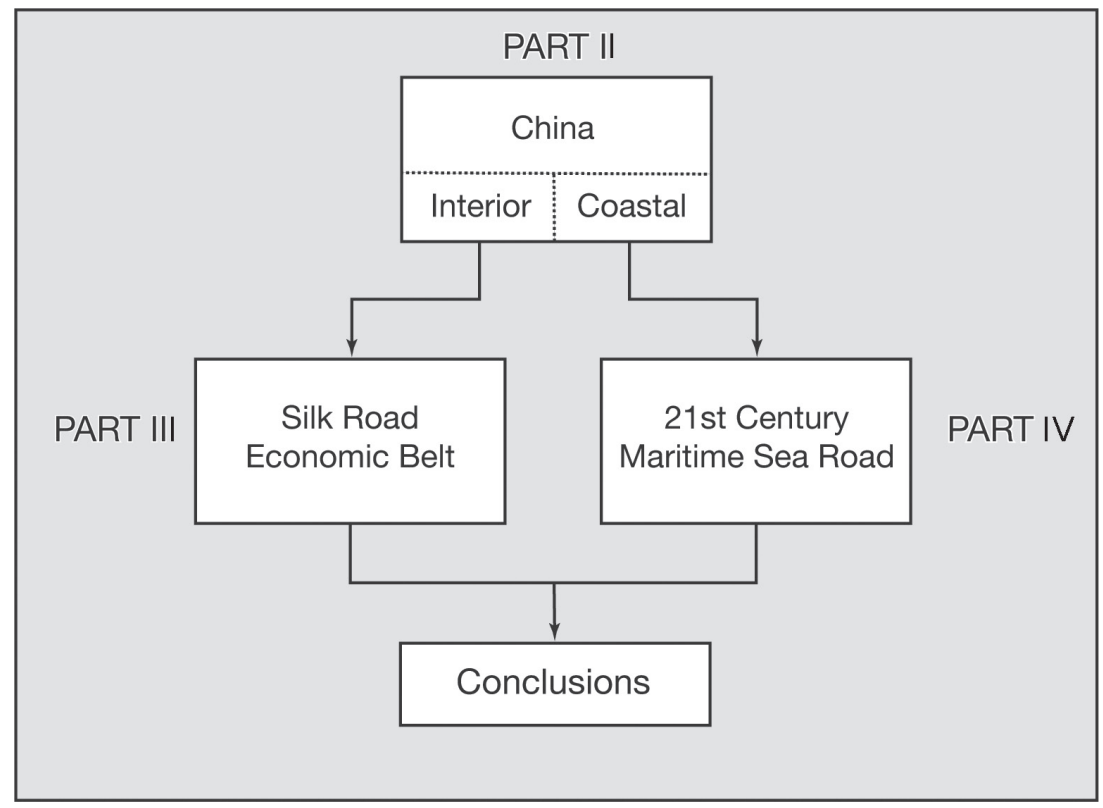

\section{Figure $1.3 \quad$ Structure of the book}

In Part III, Chapter 3 surveys the dual landbridging of Eurasia - the first involving China, Mongolia and Russia and the second covering China, Kazakhstan, Russia, Belarus and the European Union - before examining the economic corridor between China, Iran and Turkey, and the prospects of a third landbridge from India to Europe. Varying reactions to China's landbridging role in both Western and Eastern Europe, Russia, Central Asia and India are considered with reference to specific geologistics projects and key gateways. Then Chapter 4 centres upon the three secondary corridors traversing South Asia and Southeast Asia: the China-Pakistan Economic Corridor (CPEC); the China-Indochina Peninsula Economic Corridor (CIPEC), known also as the Southwest Silk Road; and the Bangladesh-China-India-Myanmar (BCIM) Economic Corridor. Illustrative geologistics projects within each of the three corridors are explored together with the reactions to China's Initiative by India.

In Part IV Chapter 5 outlines the original Maritime Silk Road's blue economic passage encompassing the Indian Ocean and the Mediterranean Sea, which focuses on geologistics projects involving seaports, the Bay of Bengal economic circle, and transport linkages between seaports and inland destinations in East Africa and the rest of Africa. Chapter 6 elaborates the Pacific 
Passage by discussing the South China Sea before exploring China's geologistics strategy in Oceania and the South Pacific, and its extension into Antarctica that has triggered adverse reactions from the United States and its allies. Chapter 7 investigates reactions to the Arctic Passage (or 'Polar Silk Road)' stemming from China's Arctic Policy (SCIO, 2018a). Chapter 8 defines the Trans-Pacific Passage linking China to Latin America and the Caribbean and discusses progress on four geologistics projects before examining the reactions of the United States.

After this three-part analysis, the study concludes in Chapter 9 by addressing progress on China's Belt and Road Initiative over its first five years, particularly the effect of this transnational policy upon China itself. Then there is an opportunity to look ahead to the Communist Party of China's two centennial goals in 2021 and 2049. Also, a comparison is made between China's geologistics model and the British imperial counterpart to gauge the degree to which Beijing's Belt and Road Initiative is unique. 